RESEARCH REPORT

\title{
Cultural identity, acculturation, and mental health among adolescents in east London's multiethnic community
}

\author{
Kamaldeep Bhui, Stephen Stansfeld, Jenny Head, Mary Haines, Sheila Hillier, Stephanie Taylor, \\ Russell Viner, Robert Booy
}

J Epidemiol Community Health 2005;59:296-302. doi: 10.1136/jech.2003.014456

See end of article for authors' affiliations

Correspondence to

Professor K Bhui, Centre for Psychiatry, Institute of Community Health Sciences, Queen Mary, London E1 4NS, UK;

k.s.bhui@qmul.ac.uk

Accepted for publication 15 September 2004

\begin{abstract}
Study objective: To investigate cultural identity as a risk factor for mental health problems among adolescents.

Design: A cross sectional school based population survey. Mental health problems were measured using the strengths and difficulties questionnaire. Pupils were classified into one of four cultural identity types on the basis of friendship and clothing choices.

Setting: East London.

Participants: 2623 adolescents (aged 11-14) from a representative sample of 28 schools in east London. Results: In comparison with marginalised adolescents who chose friends from neither their own or other cultures, fewer mental health problems were found among adolescents making culturally integrated friendship choices (friends from own and other cultures: $O R=0.6,0.4$ to 0.9 ), boys making integrated friendship choices $(\mathrm{OR}=0.45,0.22$ to 0.91$)$, and specifically among Bangladeshi pupils with integrated friendship choices $(O R=0.15,0.04$ to 0.55$)$.

Conclusion: As measures of cultural identity, integrated friendship choices overall, and specifically for boys and Bangladeshi pupils, are associated with lower levels of adolescent mental health problems.
\end{abstract}

A cculturation was first defined as "the phenomena which results when groups of individuals having different cultures come into continuous first hand contact with subsequent changes in the original cultural patterns of either or both groups". ${ }^{1}$ This process includes psychological, sociocultural, and economic acculturation. Attachment to people and places contributes to a stable place identity that is also threatened by migration and displacement. $^{2}$ Comparative studies of acculturation and adolescent mental health are uncommon despite adolescence being an especially vulnerable period of identity change. ${ }^{34}$ Furthermore, international attention to asylum seekers, refugees, immigration, and terrorism fuels debate about the best way to encourage inclusive citizenship and social integration. For example, immigration policy, social policy, and hostility towards migrants influence their acculturative choices. ${ }^{4}$ In recognition of this after race riots in the north of England there followed substantial investment in community projects with the sole objective of reducing conflict and encouraging integration (http://www.homeoffice.gov.uk/ docs/pocc.pdf). Furthermore, there are now unprecedented levels of global migration and most adolescents in urban areas mature in multicultural communities. Therefore, research on acculturation and cultural identity is necessary to inform preventive strategies to mitigate the risks of mental disorder in multicultural communities. ${ }^{56}$

Earlier studies on acculturation used proxy measures such as duration of residence, language ability, language preference, cultural orientation to daily life tasks, and ethnic self identification; these have found contradictory evidence. Although some of this work was on adults, more of the recent work has addressed the identity of adolescents for whom acculturation may represent efforts to adapt to local societies in general including reconciling cultural identities. Among Indians and Mexican Americans the duration of residence in the United States is associated with a higher lifetime risk of affective disorders, drug misuse, and dependence. $^{7}$ Foreign born adoptees to Sweden who questioned their identity or felt non-Swedish had more behavioural problems than those feeling Swedish. ${ }^{8}$ Studies of South Asians in the United Kingdom and Northern India show that parental traditionalism is associated with less deliberate self harm among South Asian adolescents, while greater acculturation is associated with higher risk of deliberate self harm among South Asian women. ${ }^{9}{ }^{10}$ In contrast with these studies showing poor mental health outcomes, a survey of Greek adolescents living in Munich and Greece and Turkish adolescents in Turkey found lower levels of mental health problems among migrants. ${ }^{11}$ An Australian study comparing native born Australians, Australian born children of immigrants, and immigrant adolescents also did not find a higher risk of mental health problems among migrants. ${ }^{12}$ Studies of Bangladeshi people in the UK, ${ }^{13}$ Mexican born immigrants to the USA, ${ }^{14}{ }^{15}$ and immigrant children in Australia all report that traditionalism may reduce the risk of mental disorders. ${ }^{16}$

Berry proposed a typology of identities after acculturation experiences in a broad range of ethnic and cultural groups. ${ }^{17}$ This model classifies people on the basis of strong or weak affiliation with host culture and culture of origin on independent dimensions. This allows for adoption of attitudes and behaviours from both the culture of origin and the newly encountered culture (integrated identity). Alternatively, both sets of attitudes and behaviours may be rejected (marginalised identity). Or host culture may be preferred over culture of origin (assimilated), and finally culture of origin may be retained and host culture rejected (traditionalism). These four types of identity show validity when investigated empirically from a number of theoretical perspectives. ${ }^{4}{ }^{18}$ Empirical studies using this model have consistently found that integration is the most healthy outcome, marginalisation is the most risky outcome, and traditionalism (also called segregation) and assimilation carried intermediate levels of risk for mental health problems. ${ }^{4}$ Using this model of identity we assessed hypotheses about associations between clinically significant 
mental health problems and cultural identity of adolescents from a range of ethnic groups.

\section{METHODS \\ Design and sample selection}

We conducted a cross sectional school based survey of a representative sample of 2790 adolescents from year 7 (11-12 years) and year 9 (13-14 years) attending schools in east London in 2001. All 42 eligible schools in the three geographically defined London boroughs were stratified by borough and school type (comprehensive, voluntary, other). Comprehensive schools are open to all children, and are banded so that there is a balance of ability across the school. Voluntary schools are mostly set up by churches or other religions and a few by charities. Thirty schools were randomly selected within strata to ensure representation by borough and school type. Within the 28 schools that agreed to take part, four representative mixed ability classes were selected (two from year 7 and two from year 9). Written informed consent was sought from each school's head teacher, and from each participating adolescent, parents were fully informed about the study and given the opportunity to opt out. In addition we met with local teachers, parents, health and social care professionals, to seek advice on the research process. The local research ethics committee approved the study.

\section{Mental health measures}

Mental health was measured using the self report strengths and difficulties questionnaire (SDQ). Although the validity of mental health outcome measures has been questioned when applied across cultures, this usually refers to diagnostic measures or psychopathological measures rather than symptom based or behavioural measures. Furthermore, the SDQ is psychometrically valid and has been used in large surveys of young people in multicultural community samples, including studies in Bangladesh. ${ }^{19-21}$ A total difficulties score (0-40) is derived by summing four subscale scores (emotional symptoms, conduct problems, peer problems, hyperactivity). Young people were considered to have "mental health problems" if they scored 17.5 or more, a threshold that is based on scores in national data where 10\% (9.4\% boys, $9.0 \%$ girls) of the sample scored within the "high scorer" band. ${ }^{20}$ This threshold in self report questionnaires distinguishes those receiving mental health services from those not receiving services and was used to classify SDQ scores to a binary outcome in analyses. ${ }^{19}$ The self report versions of this instrument show acceptable levels of correlation with parent and teacher ratings. ${ }^{19}$

\section{Ethnicity and culture indicators}

Ethnic group membership was based on self report using ethnic categories from the 2001 UK census, supplemented by questions on national group. In this paper we report data on the nine largest ethnic groups: white UK $(n=581)$, whiteother ( $\mathrm{n}=161$; white ethnic groups of non-UK origin), mixed ethnicity $(\mathrm{n}=191$; one parent was white and one nonwhite), Indian $(n=250)$, Pakistani $(n=184)$, Bangladeshi $(\mathrm{n}=690)$, black Caribbean $(\mathrm{n}=166)$, black African $(n=279)$, black British $(n=121$; total number $=2623)$. Cultural identities are expressed through choices over food, friends, leisure pursuits, and clothes. ${ }^{9}$ In this health survey we included questions on cultural preferences of friends and clothes to assess cultural identity. Friendships offer social support and group belonging, including racial group belonging. ${ }^{92}$ Clothing choices are visible markers of religious and cultural group membership and are a source of conflict between parents and children. ${ }^{23}$ We piloted the questions and conducted debriefs to ensure face and content validity, and to maximise response rates by improving the clarity and ease of completion of the questionnaire. Although we wished to use the term "culture" in the questionnaire, the term "race" was used as the pilot studies and debriefing showed that adolescents were unable to make sense of the words "culture" or "ethnic group". Adolescents understood the word race and its relation to skin colour, lifestyles, food, dress, and religion - that is, cultural elements were incorporated in their use of the term race.

We classified cultural identity on the basis of pupil's choice of friends and of clothing using four questions (appendix 1cultural identity questions). Each question had had four Likert scale items (scores 1 to 4 ). These were re-coded into binary variables using a threshold score of 2 or less to designate weak endorsement and 3 or more to designate strong endorsement of each statement. Using these questions and thresholds each pupil's binary responses reflected weak or strong identification with "own" (questions 1 and 3) and "other" cultural groups (questions 2 and 4) for any one domain (friendship or clothing). These binary variables were combined to classify pupils into one of Berry's identity categories: integration, assimilation, traditionalism, marginalisation for clothing, and friendship choices (table 1). ${ }^{17} \mathrm{We}$ also asked questions about speaking English or another language at home. Our approach assumed that clothing and friendship choices were independent measures of cultural identity. The questions were suitable for all adolescents, as the cultural identity of white adolescents living in inner city areas is also of interest if minority status can confer a greater risk of mental disorder. ${ }^{24}$

\section{Analyses and measuring confounders}

Statistical analyses were weighted to take account of unequal probabilities of selection. As the sample used a stratified cluster design with pupils clustered within schools, standard errors and 95\% confidence intervals for means and proportions were calculated using survey estimation (svy and cluster) commands available in Stata 5.0. This produces robust standard errors for the sampling strategy. Potential confounds included year group, school, borough, free school meals (a valid measure of household income ${ }^{25-27}$; parental car ownership (none or one or more as a measure of socioeconomic status), number of rooms in the home (as a measure of socioeconomic status), religion (none, Christian, Hindu, Sikh, Muslim, other), duration of stay in the UK (years), gender, and ethnic group. We also used the friends subscale of the "multidimensional scale of perceived social support" for adjustment in models in which social support may confound the relation between friendship based classification of identity and mental health problems. ${ }^{28}$ High and low social support as a binary variable was entered into the model using the median as the threshold for classification. We also stratified by gender, and by specific ethnic groups. For ethnic group subanalyses, we only reported findings reaching a significance of $p<0.01$ to reduce chance findings. In logistic regression models the marginalised group, the most morbid group, was the reference group. A gender by year group interaction was included in the

\begin{tabular}{llll}
\hline Table 1 & Berry's model of acculturation after migration \\
\hline Strong identifications with: & Other & Own \\
\hline Traditional & - & + \\
Isolated or marginalised & - & - \\
Assimilated & + & - \\
Integrated or bi-cultural & + & + \\
\hline
\end{tabular}


Table 2 Percentage of each ethnic group falling within specific acculturation levels

\begin{tabular}{|c|c|c|c|c|c|c|c|c|c|c|}
\hline & & White & $\begin{array}{l}\text { White- } \\
\text { other }\end{array}$ & Mixed & Indian & Bangladeshi & Pakistani & $\begin{array}{l}\text { Black } \\
\text { Caribbean }\end{array}$ & $\begin{array}{l}\text { Black } \\
\text { African }\end{array}$ & Black British \\
\hline \multirow{6}{*}{$\begin{array}{l}\text { Friendship } \\
\text { choices }\end{array}$} & & $n=529$ & $n=116$ & $n=165$ & $n=231$ & $\mathrm{n}=601$ & $n=165$ & $n=133$ & $n=243$ & $n=110$ \\
\hline & $\begin{array}{l}\% \text { Response } \\
\text { rate† }\end{array}$ & 91 & 72 & 86 & 92.5 & 87.1 & 89.7 & 80.1 & 87.1 & 90.9 \\
\hline & Marginalised & 14.8 & 20.1 & 19.6 & 17.4 & 14.1 & 17.1 & 11.8 & 17.8 & 13.4 \\
\hline & Traditional & 29.4 & $15.8^{\star *}$ & $17.1^{* *}$ & 22.9 & $52.5^{\star \star \star}$ & 37 & 31.8 & $20.2^{*}$ & 25.7 \\
\hline & Assimilated & 16.6 & 27 & 34.3 & 30.8 & $5.6^{* * *}$ & 12.1 & 15.1 & 20.7 & 21.3 \\
\hline & Integrated & 39.1 & 37.1 & $30^{*}$ & 29 & 27.8 & 33.8 & 41.4 & 41.3 & 39.5 \\
\hline \multirow{6}{*}{$\begin{array}{l}\text { Clothing } \\
\text { choices }\end{array}$} & Responders & $n=527$ & $n=116$ & $n=164$ & $n=231$ & $\mathrm{n}=601$ & $n=164$ & $n=131$ & $n=234$ & $n=111$ \\
\hline & $\begin{array}{l}\% \text { Response } \\
\text { rate† }\end{array}$ & 90.7 & 72 & 85.9 & 92.4 & 87.4 & 98.8 & 71.2 & 83.9 & 91.7 \\
\hline & Marginalised & 33 & 47.1 & 37.8 & 37.4 & 38.1 & 38.1 & 32.2 & 41.1 & 36.0 \\
\hline & Traditional & 36.1 & $17.9^{* * *}$ & $23.9^{*}$ & $21.1^{\star \star}$ & $21.1^{\star * \star}$ & 29.6 & 27.8 & $21.8^{* \star *}$ & 23.7 \\
\hline & Assimilated & 5.0 & 10.4 & $17.5^{\star * *}$ & $20.4^{\star \star \star}$ & $16.9^{* * *}$ & $13.7^{* *}$ & $11.1^{*}$ & $18.6^{* * *}$ & $17.4^{* * *}$ \\
\hline & Integrated & 26.3 & 24.6 & 20.8 & 21.1 & 24 & 18.7 & 28.9 & $18.6^{* *}$ & 22.9 \\
\hline
\end{tabular}

†Response rate to cultural identity questions. $p$ Values calculated from weighted LR models using marginalised group as baseline, and comparing with white ethnic group ( ${ }^{*} \mathrm{p} \leqslant 0.05 ;{ }^{* *} \mathrm{p} \leqslant 0.01 ;{ }^{* * *} \mathrm{p} \leqslant 0.001 ;{ }^{* * * *} \mathrm{p} \leqslant 0.001$ ).

final model as girls were more likely to be in year 9 than 7 $(\mathrm{OR}=1.57,1.01$ to $2.42, \mathrm{p}=0.04)$.

\section{RESULTS}

The sample

Invitation letters were sent to 3395 pupils of whom 73 were found to have left the school. Of the remaining 3322 pupils, 2790 completed a survey questionnaire (84\% response rate). At the time of survey, other non-responders were accounted for by sickness $(3 \%)$, absence because of holiday or other preagreed reason $(2 \%)$, with $7 \%$ being absent for unknown reasons. Only $0.4 \%$ of pupils refused to take part, and $3.1 \%$ of parents opted for their child not to participate in the study. Only $2 \%$ of pupils spoke no or little English at school and were assisted with completion by teachers and the research team, but language difficulties did not preclude anyone from participating. Twenty per cent $(n=525)$ of adolescents were born outside of the UK; from among these complete data on duration of stay in the UK were available for 514 adolescents. Of those not born in the UK 39\% had been in the UK for less than five years, $28 \%$ for between 6 and 10 years, 29\% for less than 10 years, and $4.5 \%$ almost all their lives. We asked about religion: $555(21.3 \%)$ expressed not having a religion, 678 (26\%) were Christian, 1137 (43.6\%) were Muslim, 87 (3.3\%) were Hindu, $68(2.6 \%)$ were Sikh, and $82(3.2 \%)$ either did not know, or gave another religious group $(n=30)$. The prevalence of eligibility for free school meals varied from $22 \%$ for Indian adolescents to $66 \%$ for Bangladeshi adolescents. Reported car ownership was lowest among Bangladeshi $(60 \%)$ and highest among Pakistani $(85 \%)$ households. The number of rooms in any household varied from 1 to 19. The mean number of rooms did not vary greatly by ethnic group. The lowest mean number of rooms (3.9) was reported for white-other and black African households; the greatest mean number of rooms was reported by pupils of Indian (4.7) and Pakistani (4.9) origin.

\section{Cultural identity}

Bangladeshi pupils had the most traditional friendship choices (table 2). South Asian groups (Bangladeshi, Pakistani, and Indian) were the least integrated. About 40\% of white and black children had same cultural and cross cultural (integrated) friendship choices. A large proportion of all young people had marginalised clothing choices. On the basis of clothing choices, in comparison with the boys, girls were more likely to be classified as traditional $(\mathrm{OR}=1.48,1.2$ to $1.84, \mathrm{p}<0.001$; see table 3 ). Gender was not significantly associated with cultural identity classification on the basis of friendship choice. We treated identity on the basis of clothing and friendship choices as independent measures on different domains of identity. In support of this approach the correlation between the two measures was low (pairwise correlation coefficient: 0.17 ) showing agreement for between 25\% (traditional) and 53\% (integrated) of pupils. Overall, there was $36.4 \%$ agreement $(\kappa=0.16)$. The pilot studies supported the face and content validity of the measures. As a test of concurrent validity we assessed whether speaking English at home was related to specific patterns of clothing and friendship choices. In comparison with adolescents with marginalised choices, those not speaking English at home were more likely to have traditional friendship choices $(\mathrm{OR}=1.5,1.19$ to $2.0, \mathrm{p}=0.001)$. In support of the conceptual basis of the variable, they were also less likely to have assimilated friendship choices $(\mathrm{OR}=0.53,0.39$ to $0.72, \mathrm{p}<0.001)$ or integrated friendship choices $(\mathrm{OR}=0.72$, 0.56 to 0.93 ). In contrast with expectation those not speaking English at home were less likely to have traditional clothing choices ( $\mathrm{OR}=0.78,0.63$ to $0.97, \mathrm{p}=0.03$ ).

\section{Gender effects}

Girls were more likely to have mental health problems ( 153 of 1331 compared with 120 of 1252; $11.5 \%$ compared with $9.3 \%, \mathrm{OR}=1.3,0.99$ to $1.7, \mathrm{p}=0.06$ ). In unadjusted analyses stratified by gender, boys with integrated friendship choices, and girls with integrated clothing choices had fewer mental health problems (table 3). On stratifying by gender and adjusting for confounds, lower levels of mental health problems were found among girls classified as having integrated clothing choices (compared with girls making marginalised clothing choices; $\mathrm{OR}=0.52,0.29$ to 0.93 , $\mathrm{p}=0.03)$, and among boys making integrated friendship choices (compared with boys making marginalised friendship choices; $\mathrm{OR}=0.45,0.22$ to $0.91, \mathrm{p}=0.03$ ).

\section{Fully adjusted analyses}

Table 4 shows that when gender is included in the fully adjusted model, the lower risk of mental health problems among those making integrated friendships is sustained. The findings for friendship choices were also sustained after adjustment for social support from friends $(\mathrm{OR}=0.61,0.39$ to $0.95, \mathrm{p}=0.03$ ). In this model high social support was also associated with some reduced risk of mental health problems $(\mathrm{OR}=0.7,0.5$ to $0.98, \mathrm{p}=0.04)$. The association between integrated clothing choices and fewer mental health problems remains non-significant. 
Table 3 Mental health problems: identity and gender

\begin{tabular}{|c|c|c|c|c|c|c|c|c|c|}
\hline \multirow{3}{*}{$\begin{array}{l}\text { Identity } \\
\text { choices }\end{array}$} & \multirow[b]{3}{*}{ Identity types } & \multicolumn{4}{|l|}{ Girls } & \multicolumn{4}{|l|}{ Boys } \\
\hline & & SDQ cases & Odds ratio & $95 \% \mathrm{Cl}$ & p Value & SDQ cases & Odds ratio & $95 \% \mathrm{Cl}$ & $p$ Value \\
\hline & & \multicolumn{4}{|l|}{ n/N (\%) } & \multicolumn{4}{|l|}{$\mathrm{n} / \mathrm{N}(\%)$} \\
\hline \multirow{4}{*}{$\begin{array}{l}\text { Clothing } \\
\text { choices }\end{array}$} & Marginalised & $50 / 416(12)$ & 1 & & & $38 / 429(8.4)$ & 1 & & \\
\hline & Traditional & $34 / 350(10.2)$ & 0.8 & 0.5 to 1.3 & 0.45 & $23 / 235$ (9.7) & 1.2 & 0.7 to 2.1 & 0.56 \\
\hline & Assimilated & $26 / 170(14.6)$ & 1.3 & 0.8 to 2.1 & 0.34 & $13 / 139(9.2)$ & 1.2 & 0.6 to 2.1 & 0.82 \\
\hline & Integrated & $18 / 256(6.8)$ & 0.5 & 0.3 to 0.99 & 0.03 & $21 / 270(7.5)$ & 1.1 & 0.5 to 1.6 & 0.67 \\
\hline \multirow{4}{*}{$\begin{array}{l}\text { Friendship } \\
\text { choices }\end{array}$} & Marginalised & $25 / 195$ (12.8) & 1 & & & $20 / 164$ (11.7) & 1 & & \\
\hline & Traditional & $38 / 377$ (9.9) & 0.8 & 0.4 to 1.3 & 0.3 & $33 / 366(8.7)$ & 0.72 & 0.4 to 1.3 & 0.28 \\
\hline & Assimilated & $31 / 234(12.8)$ & 1 & 0.6 to 1.8 & 1.0 & $18 / 157$ (11.4) & 0.97 & 0.5 to 1.9 & 0.93 \\
\hline & Integrated & $35 / 389(9.4)$ & 0.7 & 0.4 to 1.2 & 0.2 & $25 / 386(6.1)$ & 0.5 & 0.3 to 0.9 & 0.02 \\
\hline
\end{tabular}

\section{Ethnic group effects}

We stratified the fully adjusted analyses by ethnic group. Only two findings were highly significant. On friendship choices, integration was protective only among South Asians $(\mathrm{OR}=0.25,0.12$ to $0.54, \mathrm{p}<0.001)$, this finding remained significant only for Bangladeshi adolescents ( $O R=0.15$ 95\%CI: 0.04 to $0.55, \mathrm{p}=0.004)$ when stratified by specific ethnic groups. Religious group was not associated with mental health problems. There was a trend for those born outside of the UK to be more likely to have a mental health problem $(\mathrm{OR}=1.3,95 \% \mathrm{CI}$ : 1 to $1.74, \mathrm{p}=0.09)$.

\section{DISCUSSION}

\section{Mental health and integration}

Our findings suggest that integrated cultural identity based on friendship choices is related to fewer mental health problems among adolescents of all ethnic groups. This finding suggests more attention is necessary for all ethnic and cultural groups, including the white minorities in some inner city areas. There were however some specific ethnic group findings. It is known that ethnic group is a proxy for a number of structural and individual socioeconomic variables that may be more important as mediators of health outcomes. However, in our adjusted analyses integration on the basis of friendship choices remained significantly associated with a lower risk of mental health problems, even when adjusted for socioeconomic indicators, social support from friends, duration of stay in the UK, religion, age, gender, and ethnic group.

Cultural identity seems to be a more specific risk factor of importance beyond ethnic group. Previous studies used proxy measures such as duration of residence, language ability, language preference, cultural orientation to daily life tasks, ethnic self identification, perceived social acceptability, discrimination experiences, daily life interactions including choice over food, friends, and business acquaintances. ${ }^{29-31}$

An earlier view that migrants give up their own culture to adopt host culture is seen now as too simplistic and does not consider individuals' choice in selecting identities that aid coping behaviours and mitigate mental distress. ${ }^{4}$ Assumptions about acculturation are now less dogmatic about the inevitability and direction of adaptive change, allowing for diverse outcomes depending upon individual choice in the adaptation process. ${ }^{31}$ For example, intensification of traditional identity may follow a substantial period of residency in the host nation. ${ }^{31}$ Unlike this study, most acculturation scales have been developed, validated, and piloted in a single ethnic, linguistic, or cultural group,

\begin{tabular}{|c|c|c|c|c|c|c|c|}
\hline & & \multicolumn{3}{|c|}{ Friendships } & \multicolumn{3}{|c|}{ Clothing } \\
\hline & & OR & $95 \% \mathrm{Cl}$ & $\mathrm{p}$ Value & OR & $95 \% \mathrm{Cl}$ & $p$ Value \\
\hline Unadjusted & $\begin{array}{l}\text { Marginalised } \\
\text { Traditional } \\
\text { Assimilated }\end{array}$ & $\begin{array}{l}1 \\
0.73 \\
0.99\end{array}$ & $\begin{array}{l}0.49 \text { to } 1.09 \\
0.64 \text { to } 1.53\end{array}$ & $\begin{array}{l}0.13 \\
0.96\end{array}$ & $\begin{array}{l}1 \\
0.99 \\
1.21\end{array}$ & $\begin{array}{l}0.69 \text { to } 1.4 \\
0.81 \text { to } 1.8\end{array}$ & $\begin{array}{l}0.93 \\
0.35\end{array}$ \\
\hline $\begin{array}{l}\text { Age }+ \\
\text { gender by } \\
\text { year group } \\
\text { interaction }\end{array}$ & $\begin{array}{l}\text { Marginalised } \\
\text { Traditional } \\
\text { Assimilated } \\
\text { Integrated }\end{array}$ & $\begin{array}{l}1 \\
0.73 \\
0.98 \\
0.6\end{array}$ & $\begin{array}{l}0.48 \text { to } 1.1 \\
0.7 \text { to } 1.4 \\
0.41 \text { to } 0.88\end{array}$ & $\begin{array}{l}0.14 \\
0.88 \\
0.01\end{array}$ & $\begin{array}{l}1 \\
0.97 \\
1.22 \\
0.69\end{array}$ & $\begin{array}{l}0.72 \text { to } 1.32 \\
0.85 \text { to } 1.75 \\
0.46 \text { to } 1.01\end{array}$ & $\begin{array}{l}0.86 \\
0.29 \\
0.06\end{array}$ \\
\hline $\begin{array}{l}\text { Above + } \\
\text { eligible for } \\
\text { free school } \\
\text { meals, car, } \\
+ \text { rooms }\end{array}$ & $\begin{array}{l}\text { Marginalised } \\
\text { Traditional } \\
\text { Assimilated } \\
\text { Integrated }\end{array}$ & $\begin{array}{l}1 \\
0.73 \\
0.95 \\
0.56\end{array}$ & $\begin{array}{l}0.48 \text { to } 1.13 \\
0.66 \text { to } 1.37 \\
0.36 \text { to } 0.87\end{array}$ & $\begin{array}{l}0.16 \\
0.79 \\
0.01\end{array}$ & $\begin{array}{l}1 \\
0 . .97 \\
1.21 \\
0.68\end{array}$ & $\begin{array}{l}0.7 \text { to } 1.3 \\
0.86 \text { to } 1.73 \\
0.45 \text { to } 1.02\end{array}$ & $\begin{array}{l}0.83 \\
0.27 \\
0.06\end{array}$ \\
\hline $\begin{array}{l}\text { Above + } \\
\text { ethnic } \\
\text { group }\end{array}$ & $\begin{array}{l}\text { Marginalised } \\
\text { Traditional } \\
\text { Assimilated } \\
\text { Integrated }\end{array}$ & $\begin{array}{l}1 \\
0.8 \\
0.88 \\
0.56\end{array}$ & $\begin{array}{l}0.5 \text { to } 1.28 \\
0.62 \text { to } 1.24 \\
0.36 \text { to } 0.87\end{array}$ & $\begin{array}{l}0.35 \\
0.47 \\
0.01\end{array}$ & $\begin{array}{l}1 \\
0.97 \\
1.22 \\
0.68\end{array}$ & $\begin{array}{l}0.7 \text { to } 1.34 \\
0.84 \text { to } 1.78 \\
0.45 \text { to } 1.03\end{array}$ & $\begin{array}{l}0.83 \\
0.3 \\
0.07\end{array}$ \\
\hline $\begin{array}{l}\text { Above + } \\
\text { religion and } \\
\text { years in UK }\end{array}$ & $\begin{array}{l}\text { Marginalised } \\
\text { Traditional } \\
\text { Assimilated } \\
\text { Integrated }\end{array}$ & $\begin{array}{l}1 \\
0.79 \\
0.86 \\
0.57\end{array}$ & $\begin{array}{l}0.5 \text { to } 1.25 \\
0.6 \text { to } 1.23 \\
0.37 \text { to } 0.87\end{array}$ & $\begin{array}{l}0.32 \\
0.40 \\
0.009\end{array}$ & $\begin{array}{l}1 \\
0.95 \\
1.23 \\
0.7\end{array}$ & $\begin{array}{l}0.68 \text { to } 1.34 \\
0.86 \text { to } 1.76 \\
0.47 \text { to } 1.1\end{array}$ & $\begin{array}{l}0.78 \\
0.26 \\
0.09\end{array}$ \\
\hline
\end{tabular}


precluding their use in comparative research. ${ }^{32}{ }^{33}$ The implications of such work are that immigration, health, nationality, education, asylum, and social policy may encourage particular cultural identities that carry higher risks of mental health problems. ${ }^{4}{ }^{18} 3334$ In particular, policies that do not encourage integration may lead to poorer health outcomes. ${ }^{4}$

Friendships of the same or different gender and race Despite integration being healthy, segregated local communities and same culture friendship groups are common. A previous study reported that traditionalism was more common among women but this study did not explore the relation with mental distress or health. ${ }^{33}$ Traditional friendship choices may minimise the stress related to facing new dress, beliefs, diets, attitudes, religion, and lifestyle. Gender roles may also place constraints on the impact of acculturative experiences; this may explain the lower risk of mental health problems only among girls making integrated clothing choices in the partially adjusted models. It is well known that higher rates of mental health problems among girls, irrespective of cultural or ethnic origin, ${ }^{35}$ emerge during puberty and are explained by gender differences in roles, family environments, and stressful events. ${ }^{35}$ These gender related risks of psychopathology persist into adulthood, with early maturing girls being particularly prone to psychopathology, especially with additional life events and stresses. ${ }^{35-38}$ Therefore, late maturing girls may carry a lower risk of mental health problems, as this protects them from life events associated with mixed gender relationships that are characteristic of puberty. Family environments may also influence maturation, which in turn influences degree of traditionalism and integration in terms of friendships. For example, family relationships are powerful influences even on the age of menarche and puberty. ${ }^{38}$ Therefore, it is possible that protective family environments delay maturation, and this may diminish the risk of mixed gender relationships and reduce stress between adolescents and their parents. There are several other reasons why boys and girls differ on levels of attachment and intimacy, and select friends of the same gender and race. ${ }^{39-41}$ Immigrant adolescents differ from nonimmigrants in seeking more similarity between themselves and others when choosing friends. ${ }^{43}$ African Americans' ethnic identity was a more important determinant of friendship choices than either academic achievements or similarity in terms of using substances. ${ }^{22}$ More evidence for same race/ culture friendships arise from studies reporting that the cross cultural friendships of African Americans are less reciprocal than same culture friendships. ${ }^{41}{ }^{43}$ Cultural representations that are found in school education curriculums and immigration policies must be tackled to encourage integration while tackling other social processes that encourage segregation. Understanding the persistence of traditional social groups and identities is crucial for the development of

\section{Key points}

- Integrated friendship choices confer some advantage for all cultural groups

- Bangladeshi and South Asian pupils with integrated friendship choices had lower levels of mental health problems than white pupils

- Girls with integrated clothing choices and boys with integrated friendship preferences have fewer mental health problems. public health and social policies that will ensure social inclusion.

\section{Clothing choices and culture}

We found integrated clothing choices were associated with fewer mental health problems among girls, but the effect did not reach statistical significance, although the point estimate odds ratio of $0.68-0.7$ was unchanged by adjustment. Girls making integrated clothing choices may already be healthier or more able to negotiate clothing restrictions placed upon them. Alternatively, girls making integrated clothing choices may have more permissive families with whom they can negotiate a modification of cultural norms, and more permissive family environments may be associated with better mental health. Another study of clothing choice and mental distress found that those with emotional disturbances did not use clothes to influence their moods, perhaps allowing for more conformity. ${ }^{44}$ Our findings were less compelling for clothing choices. Several explanations can account for this. Clothing is linked to self esteem and clothing choices can influence mood. ${ }^{44}$ However, school uniforms, economic and religious constraints may influence these far more than personal choice. Therefore, clothing choices may be subject to more contextual influences than friendship choices. For example, not all ethnic groups have a unique dress code. Furthermore, most boys, whether from traditional families or not, wear westernised clothes. Similarly, girls may be more influenced by fashion trends or poverty rather than by identity.

\section{Limitations of the study}

Entering ethnicity into models had little impact on the associations between cultural identity measures and mental health outcomes. This may reflect similar relations between cultural identity and mental health in each of the ethnic groups, or a lack of power to detect differences in specific ethnic groups. The ethnic group subanalyses suggested that integration may be a protective factor for South Asians, and specifically for Bangladeshi pupils. However, it may be that the non-Asian ethnic categories were not culturally homogenous groups. Therefore, non-significant findings in the other groups may reflect negative confounding because of aggregation of specific ethnic groups. Alternatively, the sample sizes of other ethnic groups may be inadequate to detect an effect, or the magnitude of the effects of acculturation may vary by ethnic groups, with smaller effects not being detectable in this study. In contrast with our findings, fewer mental health problems among those choosing friends from the same culture may be expected on the basis of the ethnic density hypothesis; this predicts that living

\section{Policy implications}

- Gender roles interact with acculturation to produce different risks of mental health problems for specific cultural identities, requiring gender specific education, immigration, and social policies.

- Health, education, and social care policies that encourage integrated friendships are likely to be beneficial for the mental health of girls and boys, of all cultural groups.

- Understanding the reasons why boys and girls make traditional and marginalised friendship choices is important to unravel; marginalisation and traditionalism are common so interventions that encourage transitions to integrated friendships are needed. 
in an area with people from the same cultural group, as is the case with our Bangladeshi subjects, reduces the risk of mental health problems. ${ }^{45}$ The study was also limited by the number of domains we used; future work will need to pilot similar work using more domains of cultural identity.

\section{Future research and policy}

These findings are intriguing and argue for more research into processes of transition across identity groups, for new migrants and younger people born in migrant families in the UK, and taking account of more domains to measure identity. For adolescents, acculturation may be understood as a process of adaptation to an adult world, as well as reconciling cultural differences in proximate social groups. Such work will need qualitative and quantitative longitudinal designs, and must ensure adequate sample sizes for individual level analyses, and sampling across a range of socioeconomic contexts to enable multilevel modelling to unravel contextual contributions. Future research may also progress to measure the relation of cultural identity on a number of domains with distinct diagnostic groups, alongside the impact of life events on the onset and course of mental health problems among adolescents. ${ }^{46}{ }^{47}$ Young refugees for example, and immigrant groups to other continents will differ in their country of origin profile from migrants to the UK. This work will need to be replicated in other countries on other cultural groups. ${ }^{46}{ }^{47}$ The implications for educational policy include giving attention to exploration of cultural identity in schools, perhaps with a review of educational materials to ensure thoughtful and non-discriminatory representations of culture, but also policies in all social institutions that encourage and facilitate cultural integration.

\section{ACKNOWLEDGEMENTS}

The study was commissioned by the East London and The City Health Authority to inform their Health Action Zone. ST is funded by a DH Career Scientist award in Public Health. The data collection was funded by East London and City Health Authority. We are grateful to the support of the schools, parents, and students involved in this study.

\section{Authors' affiliations}

K Bhui, S Stansfeld, J Head, M Haines, S Hillier, S Taylor, R Booy, Barts and London Medical School, Institute of Community Health Sciences, Queen Mary University of London, UK

R Viner, Great Ormond St Hospital, London, UK

J Head, R Viner, University College London, UK

Conflicts of interest: none declared.

\section{APPENDIX 1: CULTURAL IDENTITY QUESTIONS}

The following questions are about how similar or different you feel from people in your race or ethnic group.
IS YOUR CHOICE IN CLOTHES SIMILAR TO PEOPLE FROM YOUR RACE/ETHNIC GROUP?
- 1 No
- 2 A little like them
- 3 Quite a lot like them
- 4 Mostly like them
IS YOUR CHOICE IN CLOTHES SIMILAR TO PEOPLE FROM OTHER RACES/ETHNIC GROUPS?
- 1 No
- 2 A little like them
- 3 Quite a lot like them
- 4 Mostly like them

\section{DO YOU HAVE MANY GOOD FRIENDS WHO BELONG TO YOUR RACE/ETHNIC GROUP?}

- 1 None

- 2 Some

- 3 Quite a lot

- 4 Most or all of them belong to my own race/ethnic group

\section{DO YOU HAVE MANY GOOD FRIENDS WHO BELONG TO OTHER RACES/ETHNIC GROUPS?}

- 1 None

- 2 Some

- 3 Quite a lot

- 4 Most or all of them belong to other races/ethnic groups

\section{REFERENCES}

1 Redfield R, Linton R, Herskovits MJ. Memorandum on the study of acculturation. Am Anthropologist 1936;38:149-52.

2 Fullilove MT. Psychiatric implications of displacement: contributions from the psychology of place. Am J Psychiatry 1996;153:1516-23.

3 Roberts RE, Attkisson CC, Rosenblatt A. Prevalence of psychopathology among children and adolescents. Am J Psychiatry 1998;155:715-25.

4 Berry J. Immigration, acculturation, adaptation. Applied Psychology 1997:46:5-68

5 Richmond AH. Globalization: implications for immigrants and refugees. Ethn Racial Stud 2002;25:707-7

6 Carballo M, Divino JJ, Zeric D. Migration and health in the European Union. Trop Med Int Health 1998;3:936-44.

7 Alderete E, Vega WA, Kolody B, et al. Effects of time in the United States and Indian ethnicity on DSM-III-R psychiatric disorders among Mexican Americans in California. J Nerv Ment Dis 2000;188:90-100.

8 Cederblad M, Hook B, Irhammar M, et al. Mental health in international adoptees as teenagers and young adults. An epidemiological study. J Child Psychol Psychiatry 1999;40:1239-48.

9 Bhugra D, Bhui K. The Asian cultural identity schedule: an investigation of culture and deliberate self harm. Int J Meth Psychiatr Res 2000;8:212-18.

10 Bhugra D, Baldwin DS, Desai M, et al. Attempted suicide in west London, II. Inter-group comparisons. Psychol Med 1999;29:1131-9.

11 Fichter MM, Elton M, Diallina $M$, et al. Mental illness in Greek and Turkish adolescents. Eur Arch Psychiatry Neurol Sci 1988;237:125-34.

12 Klimidis S, Stuart G, Minas IH, et al. Immigrant status and gender effects on psychopathology and self-concept in adolescents: a test of the migrationmorbidity hypothesis. Compr Psychiatry 1994;35:393-404.

13 Nazroo J. Ethnicity and mental health. London: Policy Studies Institute, 1997.

14 Holman EA, Silver RC, Waitzkin H. Traumatic life events in primary care patients: a study in an ethnically diverse sample. Arch Fam Med 2000;9:802-10.

15 Escobar JI, Hoyos NC, Gara MA. Immigration and mental health: Mexican Americans in the United States. Harv Rev Psychiatry 2000;8:64-72.

16 Davies LC, McKelvey RS. Emotional and behavioural problems and competencies among immigrant and non-immigrant adolescents. Aust N Z J Psychiatry 1998;32:658-65.

17 Berry W. Acculturation as varieties of adaptation. In: Padilla A, ed. Acculturation: theory, models and some new findings. Bolder, CO: Westview, 1980:9-25.

18 Ben-Shalom U, Horenczyk G. Acculturation orientations. J Cross Cult Psychol 2003;34:176-88.

19 Goodman R, Meltzer H, Bailey V. The strengths and difficulties questionnaire: a pilot study on the validity of the self-report version. Int Rev Psychiatry 2003; 15:173-7.

20 Goodman R, Ford T, Simmons $\mathrm{H}$, et al. Using the strengths and difficulties vestionnaire (SDQ) to screen for child psychiatric disorders in a community sample. Br J Psychiatry 2000;177:534-9.

21 Prescott-Clarke P, Primatesta P. Health Survey for England, The health of young people 1995-97. London: The Stationery Office, 1998.

22 Hamm JV. Do birds of a feather flock together? The variable bases for African American, Asian American, and European American adolescents' selection of similar friends. Dev Psychol 2000;36:209-19.

23 Ellis-Schwabe M, Thornburg HD. Conflict areas between parents and their adolescents. J Psychol 1986; 120:59-68.

24 Boydell J, van Os J, McKenzie K, et al. Incidence of schizophrenia in ethnic minorities in London: ecological study into interactions with environment. BMJ $2001 ; 323: 1336-8$

25 Health Education Authority. Young people and health: health behaviour in school-aged children. London: HEA, 1997.

26 Rogers A, Karlsen S, McCarthy M, et al. Camden and Islington Young People and Health project. Survey of health behaviours and attitudes in 99315 year olds in C \& I schools. London: Department of Epidemiology and Public Health, University College London Medical School, 1995.

27 West P, Sweeting H. Background, rationale and design of the West of Scotland 11 to 16 study. Glasgow: Medical Sociology Unit, Medical Research Council, 1996.

28 Zimet GD, Dahlem NW, Zimet SG, et al. The multidimensional scale of social support. J Pers Assess 1988;52:30-41. 
29 Arcia E, Skinner M, Bailey D, et al. Models of acculturation and health behaviours among Latino immigrants to the US. Soc Sci Med 2001;53:41-53.

30 Khavarpour F, Rissel C. Mental health status of Iranian migrants in Sydney. Aust N Z J Psychiatry 1997;31:828-34.

31 Lipson JG, Omidian PA, Paul SM. Afghan health education project: a community survey. Public Health Nurs 1995; 12:143-50.

32 Gutmann MC. Ethnicity, alcohol, and acculturation. Soc Sci Med 1999:48:173-84.

33 Ghuman PA. Acculturation of South Asian adolescents in Australia. BrJ Educ Psychol 2000·70:305-16.

34 Karlsen S, Nazroo J. Identity and Structure: re-thinking ethnic inequalities in health. In: Graham H, ed. Understanding health inequalities. Milton Keynes: Open University, 2000:38-57.

35 Criinen AA, Achenbach TM, Verhulst FC. Problems reported by parents of children in multiple cultures: the child behaviour checklist syndrome constructs. Am J Psychiatry 1999;156:569-74.

36 Hankin BL, Abramson LY. Development of gender differences in depression description and possible explanations. Ann Med 1999;31:372-9.

$37 \mathrm{Ge}$ X, Conger RD, Elder GH Jr. Pubertal transition, stressful life events, and the emergence of gender differences in adolescent depressive symptoms. Dev Psychol 2001;37:404-17.

38 Graber JA, Brooks-Gunn J, Warren MP. The antecedents of menarcheal age: heredity, family environment, and stressful life events. Child Dev 1995:66:346-59.
39 Graber JA, Lewinsohn PM, Seeley JR, et al Is psychopathology associated with the timing of pubertal development. J Am Acad Child Adolesc Psychiatry 1997;36:1768-76.

40 Claes ME. Friendship and personal adjustment during adolescence. J Adolesc 1992;15:39-55.

41 Clark ML, Ayers M. Friendship similarity during early adolescence: gender and racial patterns. J Psychol 1992;126:393-405

42 Cooksey EC, Mott FL, Neubauer SA. Friendships and early relationships: links to sexual initiation among American adolescents born to young mothers. Perspect Sex Reprod Health 2002;34:118-26.

43 Horenczyk G, Tatar M. Friendship expectations among immigrant adolescents and their host peers. J Adolesc 1998;21:69-82.

44 Sweeney MM, Zionts P. The "second skin": perceptions of disturbed and nondisturbed early adolescents on clothing, self-concept, and body image. Adolescence 1989.24:411-20.

45 Neeleman J, Wilson-Jones C, Wessely S. Ethnic density and deliberate self harm; a small area study in south east London. J Epidemiol. Community Health 2001;55:85-90.

46 McKelvey RS, Sang DL, Baldassar L, et al. The prevalence of psychiatric disorder among Vietnamese children and adolescents. Med J Austr 2002;177:410-14.

47 Sack WH, Him C, Dickason D. Twelve year follow up study of Khmer youths who suffered massive war trauma as children. J Am Acad Child Adolesc Psychiatry 1999;38:1171-9.

\section{THE JECH GALLERY}

\section{The evils of drink and the temperance pioneers}

A lcohol has periodically been regarded as a public health curse around the world. Two examples here from Cork in Ireland and from New York City illustrate some of the artefacts of the temperance movement in the 19th century.

In Cork, the Catholic priest, Father Mathew (1790-1856) attracted huge crowds to his temperance rallies and, when he moved to Liverpool, so great was his popularity that it was necessary to move to a larger church. Father Mathew is recognised by a statue in the centre of Cork.

In New York, wealthy San Francisco born dentist, businessman, and temperance crusader, Henry D Cogswell (1820-1900) proved as committed and energetic as Father Mathew. He campaigned tirelessly to promote the consumption of water rather than alcohol. Cogswell's memorial is this Temperance Fountain, erected in Tomkins Square Park in New York City.

Surrounded by a simple, classical Doric columned, open temple structure-with a stepped, pyramidal stone pediment-the structure is topped by the classical figure of Hebe, a mythical Greek water carrier (sculptor: Albert Bertel Thorvaldsen c1770-1844).

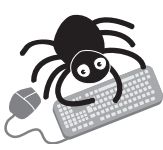

There are two additional pictures on the journal web site (http://www.jech. com/supplemental). One gives more information on the Temperance Fountain in New York and the second is a detailed view of the statue of Father Mathew in Cork.

John R Ashton

North West Public Health Team, Department of Health, 18th Floor, Sunley Tower, Piccadilly Plaza, Manchester M1 4BE, UK; johnrashton@blueyonder.co.uk
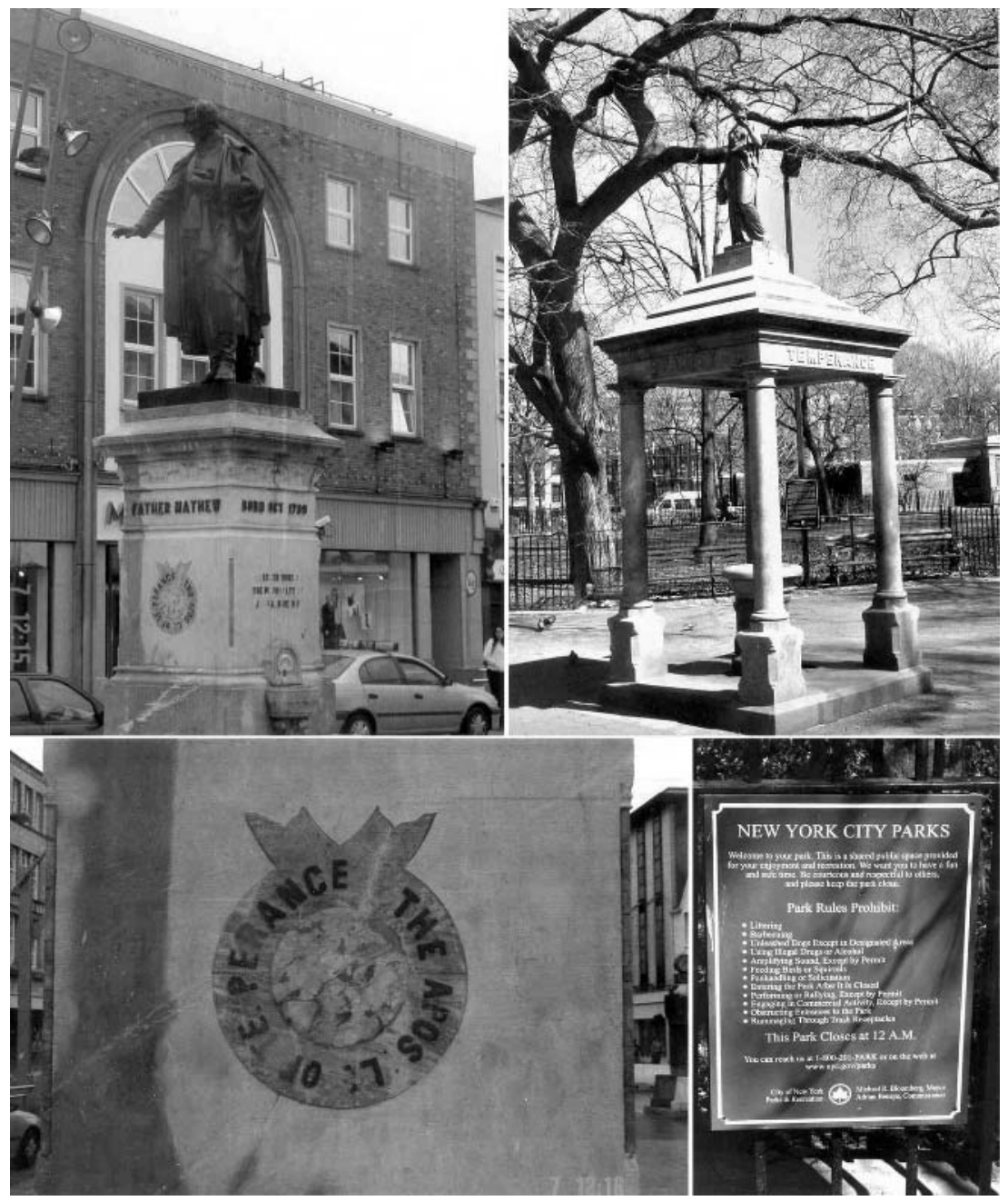